Пономарева Татьяна Александровна

кандидат социологических наук, заведующий кафедрой социально-гуманитарных дисциплин, психолого-педагогического образования и связей с общественностью Стерлитамакского института физической культуры (филиала) Уральского государственного университета физической культуры

\section{СОЦИОКУЛЬТУРНЫЕ АСПЕКТЫ ИНКЛЮЗИВНОГО ОБРАЗОВАНИЯ ДЕТЕЙ С ОГРАНИЧЕННЫМИ ВОЗМОЖНОСТЯМИ}

\section{Аннотация:}

В последние годы в отечественной высшей школе и обществе актуализируются ценности инклюзив ного образования. В статье представлен анализ состояния данного образовательного сегмента в России. Одним из необходимых условий реализации принципов инклюзии в образовательных организациях на всех уровнях является создание адаптив ной (инклюзивной) среды, которая подразумевает доступность образования для всех в плане приспособления к различным потребностям детей с ограниченными возможностями здоровья. Внедрение в инклюзивный образовательный процесс элементов социокультурной деятельности будет способствовать освоению культурных норм и образцов поведения, удовлетворению духовных запросов и потребности в общении, позитивному восприятию друг друга, изменению отношения к явлению инвалидности у субъектов инклюзивного процесса. Творческая социокультурная среда инклюзивного образовательного пространства дает возможность облегчить социализацию детей с особыми образовательными потребностями.

Ключевые слова:

инклюзивное образование, инклюзия, социальная интеграция, дети с ограниченными возможностями социокультурная деятельность, социализация.

\section{Ponomareva Tatiana Aleksandrovna}

PhD in Social Science, Head of the Department of Social Science, Humanities, Educational Psychology Training and Public Relations, Sterlitamak Institute of Physical Training (branch) of Ural State University of Physical Training

\section{SOCIAL AND CULTURAL ASPECTS OF INCLUSIVE EDUCATION FOR CHILDREN WITH DISABILITIES}

\begin{abstract}
Summary:
In recent years, the values of inclusive education have been updated in Russian education and society. The paper analyzes the status of inclusive education in Russia. The creation of an adaptive (inclusive) environment, which implies the available education for all students in terms of adapting to the different needs of children with disabilities, is a prerequisite for the implementation of inclusive principles in educational institutions at all levels. The introduction of elements of social and cultural activities into the inclusive educational process will help the actors of an inclusive process master cultural standards and patterns of behavior, meet the spiritual needs and needs for communication, will contribute to their positive perceptions of each other and change the attitude towards the phenomenon of disability. The creative social and cultural environment of the inclusive educational space makes it possible to facilitate the socialization of children with special educational needs.
\end{abstract}

Keywords:

inclusive education, inclusion, social integration, children with disabilities, social and cultural activities, socialization.

Последнее десятилетие государственной политики в области образования и здравоохранения Российской Федерации отмечено особым вниманием к гражданам с ограниченными возможностями здоровья (ОВ3). В законодательных документах обозначена необходимость создания для них одинаковых условий получения образования, коррекции нарушений развития и социальной адаптации на основе формирования максимально доступной среды, уменьшающей затруднения при участии этой категории населения в социальной жизни.

Данная задача поставлена на федеральном уровне, а также предложена ее реализация на основе программ «Доступная среда на 2016-2020 гг.», «Развитие образования на 2016-2020 гг.». Проекты предполагают адаптацию среды, в том числе образовательной, к возможностям ребенка с ОВ3, постепенную перестройку массового образования на принципы инклюзии, практика которой базируется на идеях принятия индивидуальности каждого учащегося и удовлетворения его потребностей, коррекции нарушений развития и социализации детей с ограниченными возможностями здоровья. Однако реализация программ сталкивается с рядом проблем, обусловленных противоречием между запросом государства в отношении субъектов образовательного процесса, способных создавать условия адаптивной (инклюзивной) среды, и неготовностью общества воспринимать инклюзию как обязательный компонент государственной политики.

Образование занимает особое место в жизни людей с ограниченными возможностями здоровья, выполняя важнейшие функции развития личности. С помощью образовательного процесса у данной социальной группы формируется духовная культура, раскрывается творческий потенциал, субъект интегрируется в трудовую деятельность и общество [1]. 
На сегодняшний день проблемы инклюзивного образования рассматриваются в научной литературе в законодательных, педагогических, психологических аспектах. Основные идеи в данной области отражены в трудах С.В. Алехиной, Е.Р. Ярской-Смирновой, В.П. Гудонис, А.А. Андреева, А.В. Юдаева, Т.А. Добровольской, Н.Н. Малофеева. Анализ исследований показал незначительное количество работ, раскрывающих социологические аспекты инклюзии. Инклюзивное образование в социологическом контексте представлено в работах Е.Р. Ярской-Смирновой, Т.А. Добровольской, Н.Б. Шабалиной, Д.В. Зайцева, А.Я. Чигриной [2] и др.

В частности, Е.Р. Ярская-Смирнова и И.И. Лошакова в статье «Инклюзивное образование детей-инвалидов» рассматривают опыт зарубежных стран в создании системы инклюзивного образования, анализируют законодательные, образовательные и медицинские аспекты обучения детей с ограниченными возможностями в России [3]. Т.А. Добровольская и Н.Б. Шабалина раскрывают основные условия и способы социальной интеграции людей с инвалидностью [4]. Д.В. Зайцев анализирует фрормы, содержание, условия и проблемы социальной интеграции детей с ОВ3 в общество [5]. Однако, несмотря на многочисленные подходы и технологии, можно констатировать, что инклюзивное образование так и не стало распространенным явлением в социуме, а готовность к его внедрению оставляет желать лучшего, особенно в регионах.

Л.Б. Сабитова отмечает, что гуманизация социума, которая проявляется в повсеместном распространении гуманистических идей и ценностей, находит отражение в общественном сознании, социальных отношениях и образовательной политике государства. Показателем распространения гуманистических принципов является принятый 29.12.2012 г. фредеральный закон № 273-Ф3 «Об образовании в Российской Федерации» [6], через все положения которого проходит идея гуманизации, особенно распространяющаяся на людей с ограниченными возможностями, инвалидов, нередко испытывающих дефицит гуманного отношения к себе [7, с. 75].

Поиск позитивных решений гуманистического отношения общества к личности инвалида в сфере образования обозначил в отечественном образовательном пространстве два новых понятия - «инклюзивное образование» и «особые образовательные потребности». Первое определено нечетко, однако в федеральном законе «Об образовании в РФ» оно упоминается. Инклюзивное образование - это совместное обучение (воспитание), включая организацию совместных учебных занятий, досуга, различных видов дополнительного образования лиц с ограниченными возможностями здоровья и лиц, не имеющих таких ограничений. Инклюзивное образование не отождествляется с обучением в классах (группах) компенсирующего обучения и специальных (коррекционных) классах (группах), создаваемых в образовательных учреждениях общего типа. На этой основе в настоящее время появилась тенденция рассматривать обучение в таких классах не как инклюзивное образование, а интегрированное [8, с. 124].

В ст. 2 закона «Об образовании в РФ» прописан особый правовой статус обучающегося с ОВ3 как лица, имеющего подтвержденные психолого-медико-педагогической комиссией недостатки в фризическом и (или) психологическом развитии, препятствующие получению образования без создания специальных условий. При этом инклюзивное образование должно обеспечивать равный доступ к образованию для всех обучающихся с учетом разнообразия образовательных потребностей и индивидуальных возможностей [9].

Опираясь на исследования Е.Р. Ярской-Смирновой, Л.А. Кочемасова и Н.С. Никитенко утверждают, что инклюзивное образование, «включенность, или инклюзия, - это самый подходящий термин, который можно толковать как перепланировка учебных помещений и полное реформирование школ так, чтобы они отвечали всем потребностям...» всех детей без исключения. Инклюзивное образование подразумевает, что образовательная среда должна соответствовать обучающимся с ограниченными возможностями здоровья и быть благоприятной для них [10].

Обучаясь в условиях общеобразовательных школ, ученики с особыми образовательными потребностями имеют больше преимуществ в социальной адаптации, чем их сверстники, которые приобретают знания в специальных коррекционных учреждениях. Кроме того, «здоровые» дети в условиях инклюзивной образовательной среды получают опыт социального взаимодействия с людьми с ограниченными возможностями, развивают толерантное отношение к явлению инвалидности в социуме.

Однако необходимо подчеркнуть, что модель социальной инклюзии достаточно противоречива. Во-первых, не всегда приемлема помощь другим, связанная с их включением в процесс образования (например, детям с серьезными нарушениями слуха, зрения, интеллекта). Во-вторых, сама идеология инклюзии подразумевает деление людей на «нормальных» и «других»/《нетипичных» (т. е. инвалидов, лиц с ОВ3), что искажает идею общности и равенства людей [11]. Ребенок с нарушениями будет чувствовать себя ущемленным в среде детей без инвалидности. Следовательно, нужно создать соответствующую доступную социокультурную среду, снимающую подобные барьеры. 
Политика инклюзивного образования предполагает необходимость изменения общества и его социальных институтов так, чтобы они формировали благоприятные условия для включения любого человека (в том числе с ограниченными возможностями здоровья), обеспечивающие равенство их прав, способность к самостоятельной жизни, удовлетворяющие их духовные потребности. Социокультурная модель инклюзивного процесса подразумевает, что все субъекты образовательной системы представляют собой социокультурную общность. Для эфффективного функционирования последней требуется организация творческих социокультурных сред, общего мировоззрения, культурных ценностей, которые являются результатом совместной деятельности участников инклюзивного процесса и содействуют социальной интеграции и инклюзии.

Социокультурная деятельность, как отмечает И.А. Левицкая, представляет собой целенаправленный, специально организуемый социальными институтами процесс приобщения человека к культурным ценностям социума и активного включения в него самой личности. Она характеризуется прежде всего социализирующей функцией, обеспечивающей социализацию членов общества через генерирование структуры отношений, опосредованных культурными компонентами. Это понятие складывается из трех составляющих - «социальный», «культурный» и «деятельность». В современных условиях одной из главных задач социокультурной деятельности является создание культурной развивающей среды, организованной особым образом и предназначенной для включения личности в реальную жизнь, формирования ее социальной активности [12].

Включение в инклюзивную образовательную среду элементов социокультурной деятельности - просмотра фрильмов, посещения театров, выставок, музеев, прикладного художественного и технического творчества, экологической деятельности, занятий спортом - будет способствовать освоению субъектами инклюзивного процесса культурных норм, ценностей и образцов поведения, удовлетворению духовных запросов и потребности в общении, позитивному восприятию друг друга, повышению уровня образованности.

На сегодняшний день в российском обществе существуют примеры инклюзивных образовательных проектов: «Инклюзивная школа», «Мир без преград», СТРИЖИ - «Стремление к инклюзивной жизни», «Хотим быть вместе», интегрированные театральные студии, школы инклюзивного бального танца, организуются фестивали и конкурсы. Инклюзивный проект «ВзаимоДействие» сочетает в себе элементы театра и кино, использует медийные технологии, видеоролики, документальное кино и театральные постановки с участием детей с синдромом Дауна наравне с обычными актерами. Данная программа создает положительный имидж детей с таким синдромом и направлена на изменение отношения общества к рассматриваемой социальной группе. В 2017 г. в России запущен Портал инклюзивных практик - интернет-площадка, которая представляет единую инклюзивную среду не только в онлайн-пространстве, но и в реальной жизни.

Все эти проекты демонстрируют, что социокультурные практики включены в инклюзивные образовательные проекты, а акцент в них делается на совместной культурной деятельности участников. Образовательный процесс в этом случае становится частью социокультурной среды. Вместе с образовательными программами реализуются и творческие проекты, происходят разностороннее развитие личности и интеграция в социум. Следовательно, инклюзивное образование не является синонимом лишь физического присутствия детей с особыми образовательными потребностями в одном пространстве со здоровыми детьми, а наоборот - характеризует их активную совместную работу.

Таким образом, применение социокультурного подхода к решению проблем инклюзивного образования будет способствовать расширению социального взаимодействия с людьми с ограниченными возможностями, развитию толерантности и изменению восприятия явления инвалидности. Творческая социокультурная среда инклюзивного образовательного пространства позволяет облегчить процесс социализации детей с особыми образовательными потребностями.

\section{Ссылки:}

1. Wapling L. Inclusive Education and Children with Disabilities: Quality Education for All in Low and Middle income Countries [Электронный ресурс] // CBM. 2016. Jan. P. 3. URL: https://www.cbm.org/article/downloads/54741/Quality_Education_for_All_LMIC_Evidence_Review_CBM_2016_Full_Report.pdf (дата обращения: 07.06.2018).

2. Чигрина А.Я. Инклюзивное образование детей-инвалидов с тяжелыми физическими нарушениями как фактор их социальной интеграции : дис. ... канд. социол. наук. Н. Новгород, 2011. 146 с.

3. Лошакова И.И., Ярская-Смирнова Е.Р. Социальная интеграция детей-инвалидов: к понятию инклюзивного образования // Право и образование. 2003. № 3. С. 192-204.

4. Добровольская Т.А., Шабалина Н.Б. Инвалид и общество: социально-психологическая интеграция // Социологические исследования. 1991. № 5. С. 3-8.

5. Зайцев Д.В. Социальная интеграция детей-инвалидов в современной России. Саратов, 2003

6. Об образовании в Российской Федерации [Электронный ресурс] : федер. закон от 29 дек. 2012 г. № 273-ФЗ. Доступ из справ.-правовой системы «КонсультантПлюс». 
7. Сабитова Л.Б., Крылов В.М. Инклюзивное образование в ссрере фризической культуры // Физическая культура: воспитание, образование, тренировка. 2018. № 2. С. 74-76.

8. Крылова А.В. Мотивационно-ценностный компонент инклюзивной компетентности учителя фризической культуры // Педагогико-психологические и медико-биологические проблемы физической культуры и спорта. 2017. Т. 12, № 1. С. 124-130.

9. Об образовании ...

10. Кочемасова Л.А., Никитенко Н.С. Теоретические предпосылки развития инклюзивного образования: научные исследования, практика внедрения [Электронный ресурс] // Современные проблемы науки и образования. 2015. № 2, ч. 2. URL: http://science-education.ru/ru/article/view?id=22281 (дата обращения: 07.06.2018).

11. Педагогика и психология инклюзивного образования / Д.З. Ахметова, З.Г. Нигматов, Т.А. Челнокова и др. ; под ред. Д.3. Ахметовой. Казань, 2013. 204 с.

12. Левицкая И.А. Социокультурная деятельность в системе формирования личности [Электронный ресурс] // Психология и социология. М., 2012. URL: http://www.rusnauka.com/7_NITSB_2012/Psihologia/5_103088.doc.htm (дата обращения: 07.06.2018).

\section{References:}

Akhmetova, DZ, Nigmatov, ZG \& Chelnokova, TA (et al.) 2013, Pedagogy and psychology of inclusive education, Kazan, 204 p., (in Russian).

Chigrin, AYa 2011, Inclusive education of children with severe physical disabilities as a factor of their social integration, $\mathrm{PhD}$ thesis, Nizhny Novgorod, 146 p., (in Russian).

Dobrovolskaya, TA \& Shabalina, NB 1991, 'Disabled person and society: social and psychological integration', Sotsiologicheskiye issledovaniya, No. 5, pp. 3-8, (in Russian).

Kochemasova, LA \& Nikitenko, NS 2015, 'Theoretical prerequisites for the development of inclusive education: scientific research, implementation practice', Sovremennyye problemy nauki i obrazovaniya, No. 2, part 2, viewed 07 June 2018, <http://science-education.ru/ru/article/view?id=22281>, (in Russian).

Krylova, AV 2017, 'Motivational value-based component of inclusive competence of a teacher of physical education', Pedagogiko-psikhologicheskiye i mediko-biologicheskiye problemy fizicheskoy kul'tury i sporta, Vol. 12, No. 1, pp. 124-130, (in Russian).

Levitskaya, IA 2012, 'Sociocultural activity in the system of personality development', Psikhologiya $i$ sotsiologiya, Moscow, viewed 07 June 2018, <http://www.rusnauka.com/7_NITSB_2012/Psihologia/5_103088.doc.htm>, (in Russian).

Loshakova, II \& Yarskaya-Smirnova, ER 2003, 'Social integration of disabled children: the concept of inclusive education', Pravo i obrazovaniye, No. 3, pp. 192-204, (in Russian).

Sabitova, LB \& Krylov, VM 2018, 'Inclusive education in the field of physical education', Fizicheskaya kul'tura: vospitaniye, obrazovaniye, trenirovka, No. 2, pp. 74-76, (in Russian).

Wapling, L 2016, 'Inclusive Education and Children with Disabilities: Quality Education for All in Low and Middle income Countries', CBM, January, p. 3, viewed 07 June 2018, <https://www.cbm.org/article/downloads/54741/Quality_Education_for_All_LMIC_Evidence_Review_CBM_2016_Full_Report.pdf>.

Zaytsev, DV 2003 , Social integration of disabled children in modern Russia, Saratov, (in Russian). 